\title{
Regulation of Cellular Metabolism and Hypoxia by p53
}

\author{
Timothy J. Humpton and Karen H. Vousden \\ CRUK-Beatson Institute, Glasgow G61 1BD, United Kingdom \\ Correspondence: t.humpton@beatson.gla.ac.uk; k.vousden@beatson.gla.ac.uk
}

The p53 protein is essential for the implementation of the cellular response to challenging environmental conditions. Reacting to stochastic nutrient stress, p53 integrates the activity of key metabolite-sensing pathways to coordinate an appropriate cell response. During starvation, p53 activity augments cell survival pathways, inhibits unnecessary growth, and promotes efficient nutrient generation, utilization, and conservation. Similarly, during oxygen stress, p53 facilitates redirection of cellular metabolism toward energy generation through nonoxidative means, the suppression of reactive oxygen species (ROS) generation, and ROS detoxification-promoting cell survival. However, if adverse conditions are too acute or persistent, p53 can switch roles to implement canonical cell killing. The ability of p53 to regulate metabolism is a powerful feature of p53 biology that can both promote cell survival and act as a check on the inappropriate proliferation of cancer cells.

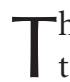
he importance of p53 is often defined by its tumor-suppressive initiation of apoptosis in cells that have accumulated DNA damage and/ or its engagement of senescence in cells harboring oncogenic mutations (Vogelstein et al. 2000; Vousden and Prives 2009). However, given the long evolutionary history of p53 and its related family members, p63 and p73, back to organisms without obvious requirements for cancer surveillance (Allocati et al. 2012), it is important to conceptualize the utility of p53 beyond tumorigenesis as a general stress monitor.

Periods of nutrient scarcity (starvation) or oxygen deprivation (hypoxia) place a significant burden on cells. Similarly, prolonged periods of nutrient or reactive oxygen overload can also negatively impact an organism (Liu et al. 2008; Circu and Aw 2010; Wellen and Thompson
2010). If left unchecked, these forces can lead to the exhaustion of finite energy reserves during starvation, cessation of normal aerobic cellular processes in hypoxia, or to failed nutrient management and metabolic syndrome in excess.

As with DNA damage, perturbations in oxygen tension, nutrient availability, or redox state can all induce p53 (Horn and Vousden 2007; Vousden and Ryan 2009). Although research into the relationship between p53 and nutrient excess is still in the early stages, the extant evidence suggests a function for p53-mediated metabolic control in this context, too. Following a metabolic shock, p53 acts to support the survival of competent cells by promoting the maintenance of cellular energy levels, the remodeling of metabolic pathways to suit prevail-

Editors: Guillermina Lozano and Arnold J. Levine

Additional Perspectives on The p53 Protein available at www.perspectivesinmedicine.org

Copyright (C) 2016 Cold Spring Harbor Laboratory Press; all rights reserved

Advanced Online Article. Cite this article as Cold Spring Harb Perspect Med doi: 10.1101/cshperspect.a026146 
ing conditions, and the cessation of cell growth and proliferation (Jones et al. 2005; Feng and Levine 2010; Scherz-Shouval et al. 2010; Maddocks et al. 2013). Although the general paradigms of $\mathrm{p} 53$ activation, including stabilization of p53 protein levels, p53 posttranslational modification, and downstream transcriptional activation of target genes, hold in response to metabolic stress, the exact molecular mechanisms are complex and can be cell-type and tissue dependent. Regardless, following activation by metabolic signals, the $\mathrm{p} 53$ protein acts as both a nuclear transcription factor to drive expression of relevant stress-response genes and a cytoplasmic and mitochondrial interaction partner with metabolic and autophagic machinery to promote adaptation and cell survival (Jones et al. 2005; Vousden and Ryan 2009; Feng and Levine 2010; Scherz-Shouval et al. 2010; Maddocks et al. 2013). Even so, if deleterious conditions are too severe or persistent, p53 switches roles to activate canonical cell death pathways (Polyak et al. 1997).

The ability of p53 to direct metabolism represents an underappreciated aspect of $\mathrm{p} 53$ function that can help to support stressed cells under adverse environmental conditions. These activities double as a further check on tumorigenesis by opposing oncogene-induced metabolic change and may play a role in the pathology of other metabolic syndromes in humans. A closer examination of the components of metabolic regulation by $\mathrm{p} 53$ during starvation and glut, and of how p53 shapes the cellular response to hypoxia and reactive oxygen are important to appreciate the broad power and utility of the p53 protein in normal and premalignant cell biology.

\section{FEAST AND FAMINE: METABOLIC SENSING AND p53}

Nutrient acquisition and resource management are critical tasks for living cells. As such, several extensive regulatory networks monitor nutrient and energy levels and act to appropriately link supplies with the demands of maintenance and proliferative programs (Fig. 1). Unsurprisingly, the ability of activated p53 to dynamically alter the metabolic state of a cell involves interactions between the $\mathrm{p} 53$ protein and various contributors to each of these metabolic pathways.

Target of rapamycin (TOR) kinase (mTOR in mammals) is a critical hub for biogenesis. The pathway senses nutrient supply—and especially amino acid levels_ and acts to promote cell growth, proliferation, protein synthesis, and transcription when conditions are favorable (Fig. 1) (Hay and Sonenberg 2004; Zoncu et al. 2011a; Laplante and Sabatini 2012). mTOR is also the master regulator of autophagy, the program of catabolic self-eating and quality control (Levine and Kroemer 2008). In mammalian cells, mTOR forms two distinct multimeric protein complexes, mTORC1 and mTORC2. Of these, the mTORC1 complex is the most relevant for metabolic regulation through its links with control of protein synthesis and translation, lipid synthesis, mitochondrial biogenesis, and autophagy through its downstream effectors (Hay and Sonenberg 2004; Laplante and Sabatini 2012).

Given its crucial role in modulating cell growth, mTORC1 activity is tightly coregulated by numerous upstream signaling pathways to ensure that mTOR is engaged only when there are sufficient nutrients, energy, and demand for biogenesis. When any of these conditions fail, mTORC1 is inhibited. In periods of low energy availability, for example, ATP depletion increases the cytoplasmic ratio of AMP/ATP, activating the energy sensor $5^{\prime}$-AMP-activated protein kinase (AMPK) and promoting AMPK-mediated inhibition of mTORC1 (Hardie et al. 2012). Similarly, in the absence of amino acids, mTORC1 fails to be recruited to endosomes and lysosomes and is, thus, spatially separated from the modulators of growth-factor signaling that allow for full mTORC1 activation (Zoncu et al. 2011b).

Reduced nutrient or energy levels result in activation of AMPK and inhibition of mTOR signaling. Because of p53-AMPK and p53mTOR pathway interactions, both situations also tend to activate p53 (Fig. 1). Activated AMPK has been shown to increase p53 transcription during glucose starvation (Okoshi et al. 2008) and to stabilize the p53 protein, at 


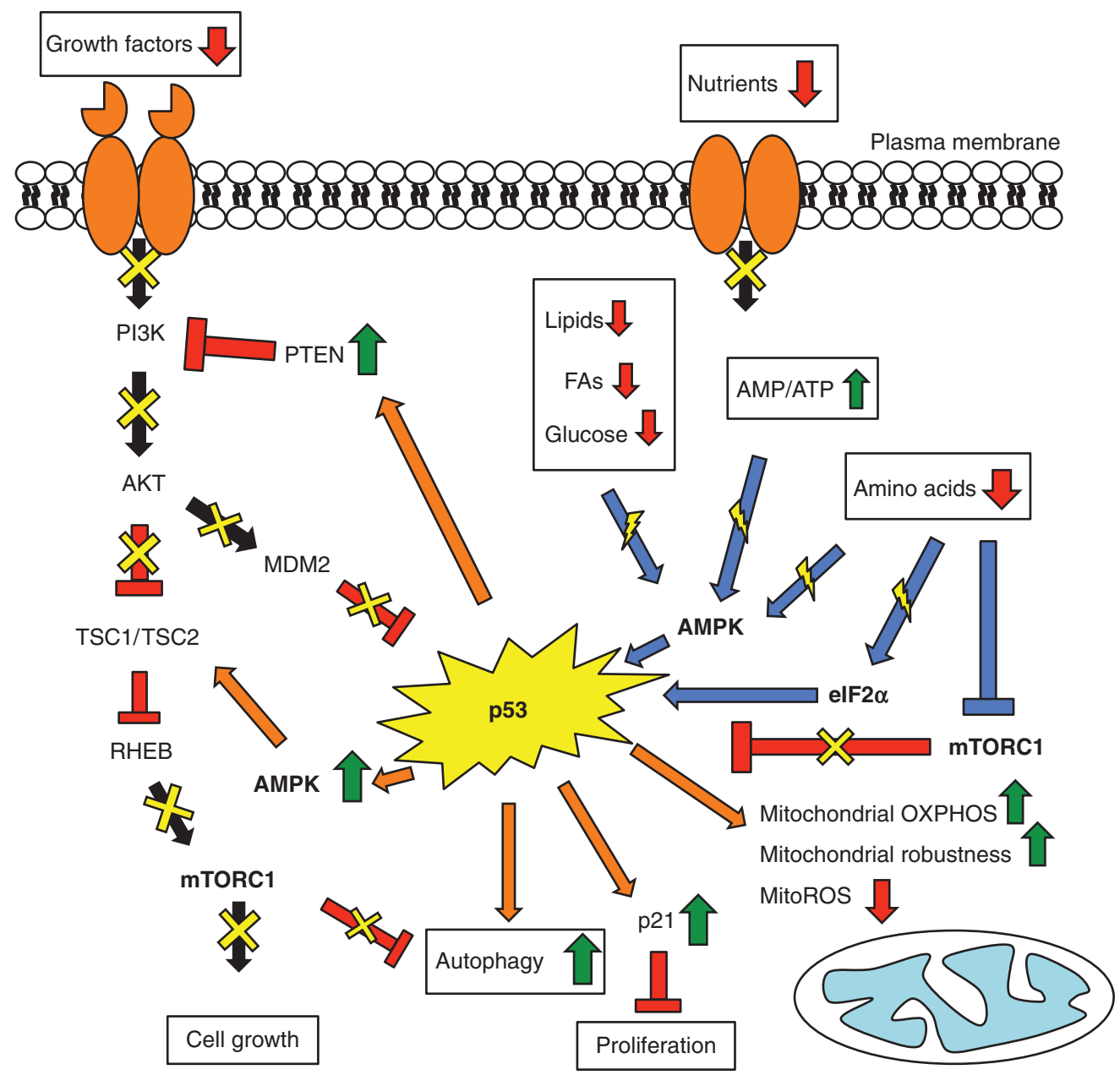

Figure 1. p53 integrates metabolic stress signals to direct cell metabolism. The p53 protein is activated in response to changing metabolic conditions (blue arrows) and growth factor signaling (black arrows) through positive and negative interactions with metabolic signaling networks including $5^{\prime}$-AMP-activated protein kinase (AMPK), eIF2 $\alpha$, the mitochondria, and mammalian target of rapamycin (mTORC1). In response to transient nutrient withdrawal, active $\mathrm{p} 53$ promotes cell survival through positive regulation of mitochondrial activity and autophagy and inhibition of mTORC1, proliferation, and cellular anabolism (orange arrows). FAs, Fatty acids; RHEB, RAS homolog enriched in brain; OXPHOS, oxidative phosphorylation; mitoROS, mitochondrial reactive oxygen species; lightning bolt, phosphorylation event; yellow cross, pathway inhibition.

least in part via AMPK-mediated phosphorylation of serine-15 on p53 (Imamura et al. 2001; Jones et al. 2005). At the same time, the relative increase in the ADP/ATP ratio that occurs in depleted cells directly increases the DNA-binding affinity of p53 and promotes p53-mediated transcription by itself (Okorokov and Milner 1999). A similar response to nutrient stress is mediated through AKT signaling. AKT is a pos- itive regulator of the ubiquitin ligase MDM2, which is responsible for the rapid proteosomal degradation of p53. Decreased AKT signaling (in response to nutrient starvation) leads to the suppression of MDM2 activity and, thus, promotes stabilization of p53 (Mayo and Donner 2001; Ogawara et al. 2002; Feng et al. 2004). Once activated by nutrient stress in this manner, p53 further inhibits mTOR signaling through 
increased transcription of many negative regulators of mTORC1 including $A M P K b, T S C 2$, and PTEN (Feng et al. 2007). These effectors, in turn, help establish a p53-dependent $G_{1}-S$ cell-cycle checkpoint arrest that prevents undue proliferation and biogenesis when metabolic conditions are inadequate.

Dynamic maintenance of cellular homeostasis requires that signaling interactions between mTORC1, AMPK, and p53 remain flexible. As such, mTORC1 activity can rapidly repress p53 when the metabolic situation improves. Increased signaling through AKT upstream of mTORC1 increases MDM2 activity and p53 degradation. Downstream from mTORC1, p53 inhibition is mediated through the action of the translation initiation factor eIF4E (Mungamuri et al. 2006). However, chronic activation of the PI3K-AKT-mTORC1 axis, as often occurs during tumorigenesis, can activate p53 and ARF (an inhibitor of MDM2 that also drives activation of p53 in response to oncogene activation) and promotes cellular senescence in an mTOR-dependent manner (Lee et al. 2007; Miceli et al. 2012). Within the regime of mild p53 activation following metabolic stress, however, the thresholds for apoptotic or prosenescent p53 activity are not reached. Instead, the balance of mTOR and AMPK signaling create transient and self-limited periods of p53 activation and subsequent inhibition of biogenesis that favor survival (Vousden and Ryan 2009; Feng and Levine 2010).

In addition to nutrient- and energy-sensing feedback loops, the metabolic activity of a cell is also regulated by the state of its mitochondrial network. During periods of starvation, mitochondrial function for ATP generation and fatty acid oxidation (FAO) are essential for survival (Dieuaide et al. 1992; Gomes et al. 2011; Hardie 2011; White 2012). As with AMPK and mTOR, the activation of p53 can alter mitochondrial capacity and function to meet changing energy demands (Fig. 1). Through the activity of p53controlled ribonucleotide reductase (p53R2), for example, p53 can regulate mitochondrial DNA copy number and increase mitochondrial mass (Bourdon et al. 2007). At the transcriptional level, active p53 augments mitochondrial function by inducing expression of SCO2, a copper transporter that is critical for proper assembly of cytochrome $c$ oxidase (COX) in the mitochondria (complex IV in the mitochondrial oxidative phosphorylation electron transport chain), as well as elements of subunit 1 of the COX complex (Okamura et al. 1999; Vahsen et al. 2004; Matoba et al. 2006; Stambolsky et al. 2006; Sinthupibulyakit et al. 2010). Increased levels of SCO2 support enhanced oxidative phosphorylation (Matoba et al. 2006). Similarly, p53 promotes increased mitochondrial function and integrity through regulation of mitochondrial quality and turnover (mitophagy). This occurs directly, through the increased expression of mitochondria-eating protein (MIEAP), and indirectly through p53mediated augmented autophagy (Kitamura et al. 2011). In addition, p53 itself can interact with PGC- $1 \alpha$ to preferentially activate the expression of many metabolic, antioxidant, and pro-cell-cycle arrest genes that facilitate growth inhibition, suppression of damaging reactive oxygen, and greater control over mitochondrial activity (Sen et al. 2011).

\section{FEAST AND FAMINE: THE ROLE OF p53 IN CARBOHYDRATE, LIPID, AND AMINO ACID METABOLISM}

As long as metabolic stress is short-lived, the interactions between the mTOR and AMPK nutrient-sensing pathways, p53, and the mitochondria promote cessation of cell growth and enhanced cell survival. Even so, a cell experiencing these conditions must also alter normal metabolic programs to promote nutrient conservation. Here again, the activation of p53 supports resilience by altering the metabolism of carbohydrates, lipids, and amino acids.

Glucose is an important carbon source for mammalian cells. Under normal conditions, glucose uptake is followed by its stepwise processing to pyruvate by glycolytic enzymes in the cytosol. Although these reactions generate a small amount of net ATP energy for the cell, it is the subsequent oxidation of pyruvate within the mitochondrial tricarboxylic acid (TCA) cycle that creates the bulk of glucose-derived ATP 
via highly efficient oxidative phosphorylation (OXPHOS) (Fig. 2) (Voet and Voet 2011). Rapidly proliferating cells, including cancer cells, metabolize glucose differently from quiescent cells (Warburg 1956). Whereas quiescent cells preferentially funnel glucose-derived pyruvate into the mitochondria to efficiently generate ATP through OXPHOS, rapidly proliferating and cancer cells depend more on increased rates of aerobic glycolysis for ATP production, converting pyruvate to lactate rather than feeding the TCA cycle (Warburg 1956; Vander Heiden et al. 2009).

Aerobic glycolysis is less efficient than mitochondrial respiration at generating ATP from glucose (Voet and Voet 2011). Even so, a switch to glycolysis may have several advantages for rapidly proliferating cells. Glycolytic intermediates can be channeled through alternative pathways to provide precursors for the de novo synthesis of amino acids, nucleotides, and lipids to meet the demands of proliferation. The pentose phosphate pathway (PPP), for example, provides ribose-5-phosphate for nucleotide synthesis and also produces nicotinamide adenine dinucleotide phosphate (NADPH), a crucial reducing agent that helps to maintain the redox status of a cell by facilitating the regeneration of reduced glutathione (GSH) (Dröge 2002; Martin and Teismann 2009). NADPH is also required for lipid biosynthesis (Fig. 2). Similarly, diverted glucose is consumed in the hexosamine pathway to provide the amino sugars required for increased glycosylation during biogenesis (Schleicher and Weigert, 2000; Moremen et al. 2012). High rates of glycolysis can also provide sufficient ATP for a rapidly proliferating cell without the requirement for OXPHOS, thus allowing survival under hypoxia and limiting the generation of potentially damaging mitochondrial ROS even when oxygen is not limiting. Furthermore, modeling studies suggest that molecular crowding can limit the efficiency of mitochondrial ATP production - an effect that could be detrimental in rapidly dividing cells and would necessitate increased ATP generation via nonoxidative pathways like glycolysis (Vazquez and Oltvai 2011; Vazquez et al. 2011).
Even though proliferating cells eschew the economy of OXPHOS for ATP generation, they do not eliminate mitochondrial function altogether. TCA-cycle intermediates are required for some anabolic reactions and can be exported from the mitochondria to support biogenesis (Vander Heiden et al. 2009; Le et al. 2012; Son et al. 2013). Consequently, at least in vitro, proliferating cells can use alternative carbon sources such as glutamine (which also provides nitrogen) in place of glucose to maintain TCA metabolite pools via anaplerotic pathways. Glutamine anaplerosis to fuel mitochondrial TCA is important for the growth of some cancer cells in vitro and may also occur in normal cells during periods of high energy demand (Bowtell and Bruce 2002; Wang et al. 2010; Le et al. 2012; Son et al. 2013; Saqcena et al. 2014). Given these observations, it is perhaps unsurprising that glutamine starvation is toxic for rapidly proliferating cells in culture. It has been reported that p53 is activated by protein phosphatase 2A (PP2A) during glutamine withdrawal and that resultant p53 activity promotes cell survival (Reid et al. 2013). These observations are exactly in line with reported roles for p53 during glucose starvation. In both cases, when nutrient conditions deteriorate, reckless carbohydrate consumption must be swiftly constrained and regulated. The p53 protein plays an important role in this process.

As with its opposition of mTORC1 signaling, p53 induction counteracts glucose profligacy by attenuating aerobic glycolysis, promoting OXPHOS, and altering PPP flux when glucose is limiting (Fig. 2). The protein Tp53induced glycolysis and apoptosis regulator (TIGAR) is a p53 target gene in humans that plays a role in this regulation. Phosphofructokinase 1 (PFK1) catalyzes the third step of glycolysis by promoting the conversion of fructose6-phosphate into fructose-1,6-bisphosphate. PFK1 is inhibited by the accumulation of metabolites that imply sufficient energy, such as ATP, but is activated by harbingers of energy depletion including AMP and fructose-2,6-bisphosphate. During glucose starvation, TIGAR (as a fructose-2,6-bisphosphatase) and the bisphosphatase arm of the bifunctional enzyme 
T.J. Humpton and K.H. Vousden

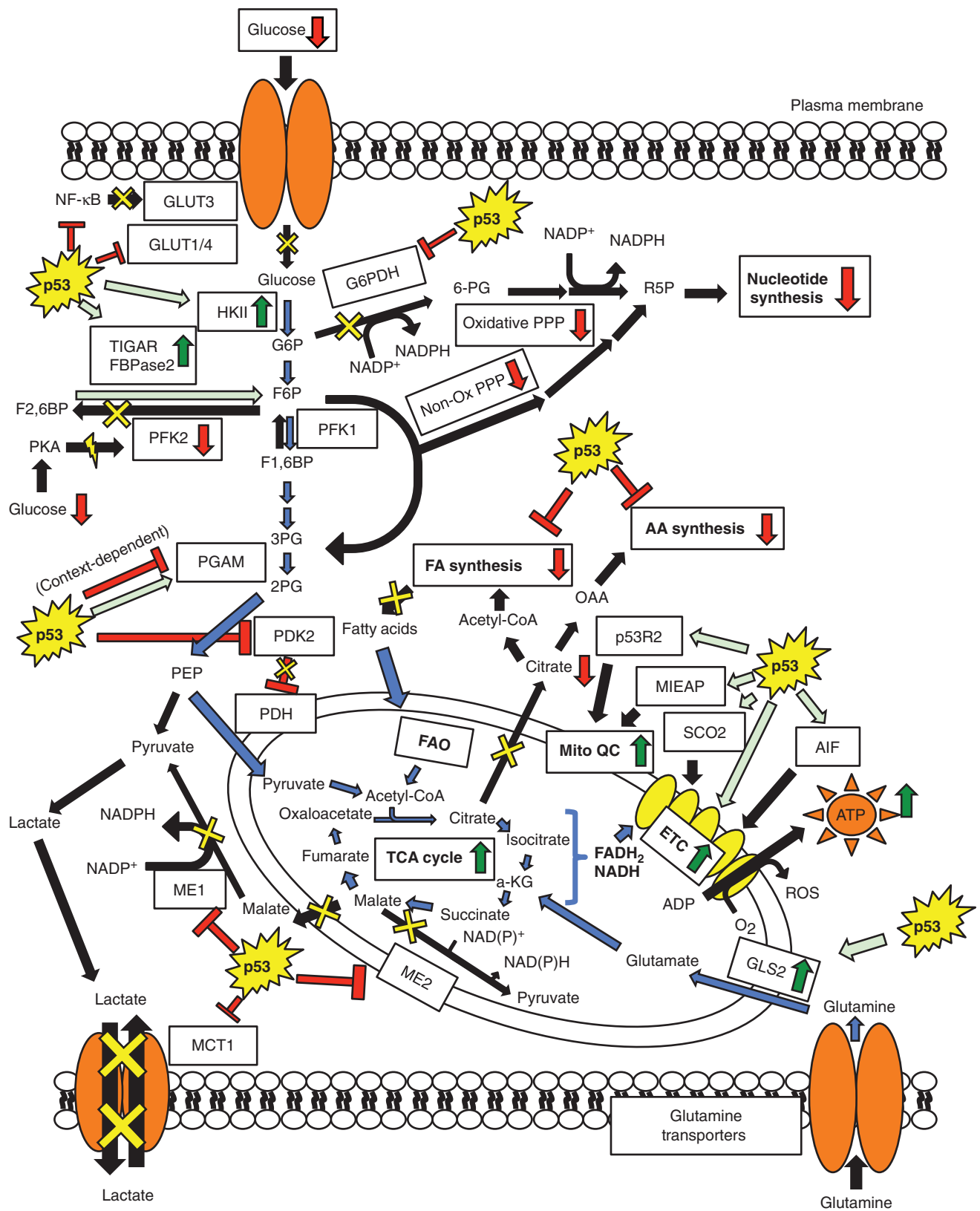

Figure 2. p53 regulates carbohydrate metabolism during glucose starvation. During glucose starvation, p53 acts to promote mitochondrial respiration (blue arrows) through numerous mechanisms including enhanced pyruvate flux into the tricarboxylic acid (TCA) cycle, increased fatty acid oxidation (FAO), decreased TCA metabolite export, greater mitochondrial quality control, more robust electron transport chain activity, and utilization of glutamate as an alternative carbon source for respiration. p53 also limits glycolysis and suppresses undue nucleotide, amino acid, and fatty acid synthesis through many pathways. TIGAR, Tp53-induced glycolysis and apoptosis regulator; HKII, hexokinase II; G6PDH, glucose-6-phosphate dehydrogenase; PPP, pentose phosphate pathway; NADPH; nicotinamide adenine dinucleotide phosphate; PKA, protein kinase A; PGAM, phosphoglycerate mutase; FA, fatty acid; AA, amino acid; MIEAP, mitochondria-eating protein; FAO, fatty acid oxidation; AIF, apoptosis-inducing factor; ME, malic enzyme. 
phosphofructokinase 2/fructose-2,6-bisphosphatase (PFK2/FBPase2) both limit fructose-2,6-bisphosphate levels by promoting its conversion back into fructose-6-phosphate (Fig. 2). These actions, in turn, decrease the activity of PFK1, restrict glycolytic flux, and promote glucose flux into the PPP (Claus et al. 1984; Bois-Joyeux et al. 1987; Kurland and Pilkis 1995; Bensaad et al. 2006; Li and Jogl 2009; Mor et al. 2011).

Alongside TIGAR, p53 dampens glycolytic flux during glucose starvation by altering transcription of several glycolytic enzymes downstream from PFK1. Targets including phosphoglycerate mutase (PGAM), the enzyme responsible for the conversion of 3-phosphoglycerate into 2-phosphoglycerate, and pyruvate dehydrogenase kinase 2 (PDK2), an inhibitor of the pyruvate dehydrogenase complex (PDC) and, therefore, of glucose flux into the mitochondria, are both suppressed (Fig. 2) (Kondoh et al. 2005; Contractor and Harris, 2012). Some care must be taken when considering the activities of p53 to limit glycolysis during starvation, however, because although the observation that p53 inhibits PGAM is true for fibroblasts undergoing starvation, for example, it has also been shown that PGAM can be induced by p53 in cardiac muscle tissue during development (Ruiz-Lozano et al. 1999). As with many aspects of p53 biology, it seems that tissue and nutrient context play important roles in determining how p53 activity alters glycolysis.

In step with limiting glycolytic flow during periods of glucose scarcity, p53 actively promotes increased mitochondrial OXPHOS for the glucose that remains. As discussed earlier, during starvation p53 acts both directly and indirectly to maintain mitochondrial function by inducing mitochondrial biogenesis, augmenting mitochondrial quality-control monitoring, and increasing the expression of mitochondrial electron transport chain components (Okamura et al. 1999; Vahsen et al. 2004; Matoba et al. 2006; Stambolsky et al. 2006; Sinthupibulyakit et al. 2010). Beyond these structural enhancements, p53 promotes increased TCAcycle turnover through induction of glutaminase 2 (GLS2), a mitochondrial catalyst for the conversion of glutamine to glutamate. Greater GLS2 activity can fuel the TCA cycle by increasing the concentration of glutamate for conversion into $\alpha$-ketoglutarate, a TCA feedstock (Hu et al. 2010; Suzuki et al. 2010). In addition, active p53 can repress expression of malic enzyme (ME1 and ME2) (Jiang et al. 2013). Doing so decreases the conversion of TCA-cycle malate into pyruvate and may block the escape of mitochondrial malate back into the cytoplasm (Fig. 2). In proliferating cells, malic enzyme activity is useful for siphoning malate back into the cytoplasm where it can be used for lipogenesis, glutamine metabolism, and NADPH production. In cancer cells, the effect of ME suppression is increased AMPK activity, diminished NADPH production, and decreased MDM2 activity-further enhancing p53 induction in a feedforward loop and promoting cancer cell senescence (Jiang et al. 2013). However, how the repression of ME contributes to the response of untransformed cells during nutrient starvation requires further investigation.

In addition to modulating glucose flux during glucose starvation, p53 can also regulate glucose production and attenuate the expression of metabolite transporters to limit glucose uptake. It has been shown in cancer cells, for example, that p53 directly represses the glucose transporters GLUT1 and GLUT4 and helps to facilitate the indirect suppression of GLUT3 expression through p53 inhibitory interactions toward NF-кB (Schwartzenberg-bar-yoseph et al. 2004; Kawauchi et al. 2008). Similarly, it has been shown in liver cells that p53 can promote the expression of gluconeogenesis-related genes and enhance de novo liver glucose production (Goldstein et al. 2013). In the system examined, induction of glucose production and its subsequent export from the liver served a metabolic tumor suppressive function by limiting the availability of glucose-derived carbon for glycolysis and biogenesis in precancerous cells (Goldstein et al. 2013). If p53 enhances gluconeogenesis during glucose starvation, this pathway could help to prop up failing glucose reserves by facilitating the catabolism of noncarbohydrate carbon sources to maintain glu- 
cose availability. This possibility will need to be examined further.

As with GLUT inhibition, the activity of $\mathrm{p} 53$ to limit expression of monocarboxylate transporter 1 (MCT1), the primary route of lactate influx/efflux in a cell, is also an important metabolic p53 tumor suppressive activity (Boidot et al. 2012). MCT1 inhibition helps to restrict the glycolytic rate in premalignant cells by abrogating lactate transport. Although most research into the role of p53-mediated modulation of glucose and lactate transport has been conducted in cancer cells, it is plausible that such responses would limit a normal cell's pursuit of nonexistent exogenous glucose or on inefficient aerobic glycolysis during starvation.

Lipid stores must also be managed in the same careful fashion as carbohydrates to maintain cell viability when nutrients become scarce. Lipids are required to maintain cell membrane integrity, for energy storage, and for signaling. In cells, lipids mainly exist as fatty acids (FAs). FA synthesis is an energy-intensive process that consumes ATP, NADPH, and two-carbon units to build and elongate the FA carbon chain (Voet and Voet 2011; Santos and Schulze 2012). Fatty acid oxidation (FAO), in contrast, releases stored energy by breaking down FAs into constitutive two-carbon units, acetyl-CoA, and reducing equivalents of $\mathrm{NADH}$ and $\mathrm{FADH}_{2}$. The products of FAO are then passed directly into the mitochondrial TCA cycle to produce ATP. Given the opposing natures of FA synthesis and $\mathrm{FAO}$, these activities are strictly segregated to different cellular compartments and tightly regulated so that futile cycling does not occur.

Just as with carbohydrate metabolism, p53 plays an important role in the regulation of lipid metabolism during periods of nutrient stress (Fig. 3). When cells are energy-depleted, p53 promotes increased FAO and suppresses FA synthesis. It has been reported, for example, that the activation of p53 in the liver and its subsequent transactivation of malonyl-CoA decarboxylase (MCD) is important for the appropriate activation of FAO in fasted mice (Liu et al. 2014). In addition, p53 directs the transcription of carnitine palmitoyltransferase 1C (CPT1C) and other carnitine acetyltransferases that im- port FAs into the mitochondria for FAO (Zaugg et al. 2011; Goldstein and Rotter 2012). Further along, p53 also activates Acad11, an acyl-CoA dehydrogenase that catalyzes the initial step of the FAO cycle in the mitochondria (Jiang et al. 2015). At the same time, p53 suppresses sterol regulatory element-binding protein 1 (SREBP1), a master transcriptional regulator of FA synthesis both through direct repression and indirectly by increasing the expression of LIPIN1, an SREBP inhibitor (Yahagi et al. 2003; Assaily et al. 2011; Peterson et al. 2011). In this manner, starvation-activated p53 prevents energy-intensive FA synthesis and repurposes FA stores for energy production through oxidation in the mitochondria. These actions promote cell survival and oppose cancer metabolism.

Rounding out the primary metabolite classes, amino acids are also required for cell growth as important precursors for the biosynthesis of proteins, nucleotides, and other biological compounds. Essential amino acids cannot be synthesized by humans and must be obtained through the diet. Nonessential amino acids can either be obtained from dietary sources or synthesized directly within the cell (Voet and Voet 2011). Amino acid depletion can have deleterious consequences for a cell and, as with carbohydrates and lipids, an insufficient supply can activate the p53-mediated stress response to promote cell survival and the efficient use of remaining amino acid stores (Fig. 3).

A decrease in amino acid concentrations suppresses mTOR pathway activity by deactivating $\mathrm{mTORC1}$ and activating other amino acid sensors such as eIF2 $\alpha$ (Clemens 2001; Wek et al. 2006). As with mTOR suppression, active eIF $2 \alpha$ inhibits protein translation and increases transcription of amino acid transporters and glutathione synthesis enzymes to promote a robust stress response. At the same time, and likely as a consequence of the actions of eIF $2 \alpha$ and AMPK and the suppression of mTOR, p53 is engaged. Once activated, p53 can induce various responses to help cells survive amino acid starvation. After depletion of exogenous serine, for example, p53 acts to prevent cell proliferation by inducing a p21-dependent, $\mathrm{G}_{1}-\mathrm{S}$ cell- 

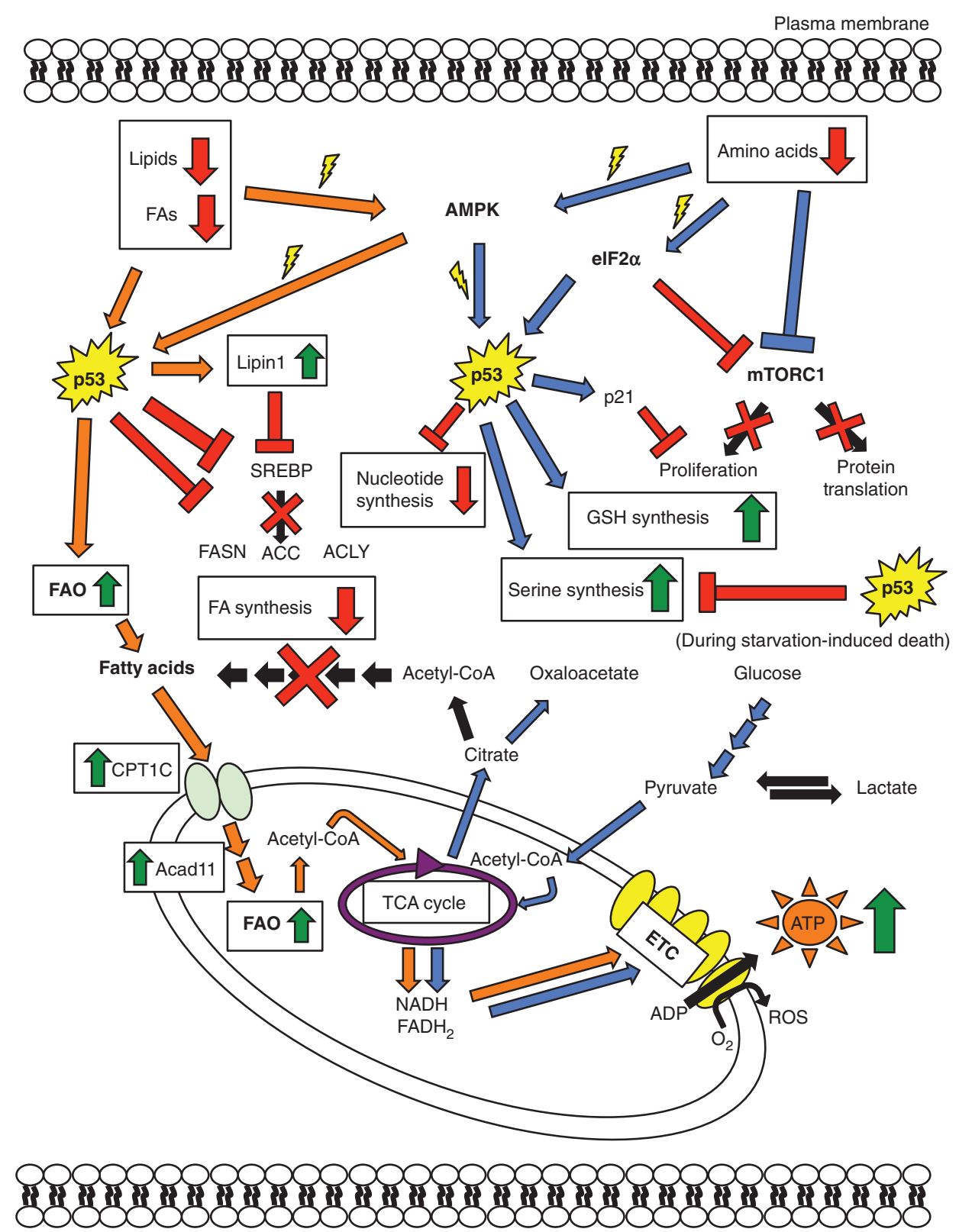

Figure 3. p53 directs lipid and amino acid metabolism during stress. In response to a shortage of lipids (orange arrows) or serine (blue arrows), p53 is activated by nutrient-sensing pathways including $5^{\prime}$-AMP-activated protein kinase (AMPK) and eIF2 $\alpha$. For lipids, p53 acts to suppress fatty acid synthesis and promote increased fatty acid oxidation (FAO) to maintain mitochondrial respiration. Similarly, serine withdrawal causes p53 to promote cell-cycle arrest, increased glutathione production, and decreased nucleotide synthesis to conserve remaining stores. FAs, Fatty acids, mTOR, mammalian target of rapamycin; SREBP, sterol regulatory elementbinding protein; GSH, glutathione; AA, amino acid; FASN, fatty acid synthetase; ACC, acetyl-CoA carboxylase; ACLY, ATP citrate lyase; FA, TCA, tricarboxylic acid; ROS, reactive oxygen species; lightning bolt, phosphorylation event; red cross, pathway inhibition. 
cycle arrest, while the cell mobilizes de novo serine synthesis. p53 limits the flux of serine into nucleotide synthesis, diverting the low levels of serine that remain principally toward glutathione production (Maddocks et al. 2013). It is thought that these maneuvers allow the cell to maintain its pool of GSH for antioxidant defense, while also preventing futile and underresourced production of nucleotides. In agreement with this hypothesis, serine-starved cancer cells that lack p53 show increased cell death, depleted glutathione pools, and an inability to halt serine-driven nucleotide synthesis (Maddocks et al. 2013). As a slight caveat to this model, it has also been reported that p53 can inhibit de novo serine synthesis in serinestarved melanoma cells through repression of phosphoglycerate dehydrogenase (PHGDH), thus promoting cell death (Ou et al. 2015). Although this observation is in contrast to the concept of a generally protective role for p53 during amino acid starvation, it is likely that the opposed outcomes reflect some degree of context specificity and underlying differences in the level of p53 induction in each experiment, leading to divergent outcomes.

A suite of sentinel proteins including AMPK, mTOR, and eIF2 $\alpha$ constantly coordinate the amounts of available metabolic building blocks with cell growth and maintenance activities. When a shortage in any metabolite class occurs, the front-line sensors transduce this information to $\mathrm{p} 53$ and promote activation of its metabolic regulatory functions (Figs. 13 ). In each case, metabolic-induced p53 activation facilitates broad changes to metabolic flux, mitochondrial activity, protein turnover, and redox status that support viability during limited nutrient availability. If conditions improve, transient p53 metabolic controls are lifted and cells can quickly reestablish normal operation. If they do not, p53 can switch roles to promote orderly cell death.

\section{FEAST AND FAMINE: AUTOPHAGY AND p53}

Autophagy is covered comprehensively in an article by White (2016), but it is important to emphasize that this process is a crucial compo- nent of the cellular response to nutrient stress. During periods of scarcity, autophagy can provide cells with a source of energy and biomaterials to sustain essential cellular functions ( $\mathrm{Ra}-$ binowitz and White 2010).

As with many aspects of p53 biology, the relationship between p53 and autophagy is complicated and reflects tissue and context-specific factors, as well as the cellular localization of p53 (nuclear vs. cytoplasmic) (Tasdemir et al. 2008; Morselli et al. 2009; Maiuri et al. 2010). For the purposes of this review, it is sufficient to mention that in normal cells, the concerted activity of p53 is generally sufficient to promote sustainable levels of autophagy in support of cell survival. Further information on the fascinating nuances of the relationship between p53 activity and autophagy can be found in White (2016).

\section{FEAST AND FAMINE: NUTRIENT EXCESS AND p53}

The consequences of a breakdown in the organismal response to nutrient excess can be clearly seen by considering the alarming increase of metabolic syndrome in humans in the $21 \mathrm{st}$ century-a direct response to chronic overconsumption (Huang 2009; Frisardi et al. 2010; Kaur 2014). Troublingly, metabolic syndrome increases the incidence of cardiovascular disease, type II diabetes, liver disease, and cancer in afflicted individuals_-significantly contributing to the ballooning worldwide healthcare burden (Huang 2009; Frisardi et al. 2010; Kaur 2014).

At its core, metabolic syndrome represents a failure of normal energy utilization and storage. As such, the phenotypes associated with metabolic syndrome are illustrative of the deleterious effects of chronic, as opposed to transient, application of excess nutrient stress. As with starvation and energy-depletion, emerging research suggests a link between p53 and the cellular response to nutrient excess. It has been shown, for example, that abnormal expression of p53 can promote insulin resistance, glucose intolerance, increased liver lipid levels, and higher levels of ROS in various mouse models-mirror- 
ing many hallmarks of metabolic syndrome (Minamino et al. 2009; Armata et al. 2010; Derdak et al. 2011; Jiang et al. 2011).

For the moment, the molecular role of p53 in mediating the cellular response to nutrient excess remains unclear and may be cell-type specific. For example, while hyperglycemia can activate p53 to promote p38 MAPK and p53dependent cell death in myocytes; hyperglycemia can also suppress p53 apoptotic activity in cancer cells (Fiordaliso et al. 2001; Garufi and D'Orazi 2014). In addition, humans that carry p53 polymorphisms that modulate $\mathrm{p} 53$ function exhibit altered susceptibility to type II diabetes and other metabolic disorders (Gaulton et al. 2008; Burgdorf et al. 2011). Based on these initial observations, it seems likely that similar avenues of influence that characterize p53-mediated control of metabolism in response to nutrient scarcity are also important for transient adaptation to conditions of nutrient excess. Future work on this frontier of $\mathrm{p} 53$ function will be important for characterizing the role of p53 across a range of physiological conditions beyond tumor suppression in cancer.

\section{RAREFIED AIR: REDOX MANAGEMENT AND p53}

As with nutrients, shocks of either too little oxygen, as in hypoxia, or of too much reactive oxygen, as during reperfusion injury or ROS stress, can engage p53. Based on evidence of the high ROS burden observed in $\mathrm{p} 53^{-/-}$mice (Sablina et al. 2005), it is intuitive that the activity of p53 in cells would be to limit ROS levels and to promote ROS detoxification (Fig. 4). In the case of mild induction of p53, as during transient oxygen stress, this appears to be the case (Budanov 2011). However, when the ROS burden of a cell is too great, the apoptotic arm of p53 is engaged, increasing ROS levels further and promoting cell death (Fig. 4) (Hammond and Giaccia 2005; Liu et al. 2005; Tu et al. 2009).

ROS are defined as oxygen-containing reactive molecules. ROS generation and metabolism are important aspects of normal cell biology. ROS are produced, for example, as a by-product of mitochondrial respiration, through enzymat- ic reactions by cellular oxidases and as a consequence of detoxification reactions involving cytochrome P450 enzymes (Lau et al. 2008). As the name suggests, ROS are highly reactive and will readily oxidize DNA, proteins, and lipidspotentially altering the function of these molecules. Although ROS are generally conceptualized as a negative for cells, controlled ROS are required for some aspects of cellular signaling and can also be important to promote growth and proliferation (D'Autréaux and Toledano 2007; Sena and Chandel 2012). Thus, ROS levels must be tightly regulated to ensure proper cellular function.

To neutralize excessive ROS and maintain the intracellular redox state, cells have developed comprehensive detoxification systems. These pathways generally rely on glutathione as a crucial cofactor to defuse ROS. During ROS detoxification, GSH is oxidized to form glutathione disulphide (GSSG) so that the ROS can be reduced (and thus detoxified). GSSG can then be re-reduced by glutathione reductase to recover GSH as long as sufficient reducing equivalents of NADPH are available (Dröge 2002; Martin and Teismann 2009).

Oxidative stress can induce protective aspects of p53 activity that function to shield the cell from ROS damage through induction of a suite of antioxidant programs (Fig. 4). For example, activation of TIGAR and suppression of glycolytic flux can combine to increase PPP activity and the production of NADPH during ROS stress. Because NADPH is required for the regeneration of GSH, p53-driven PPP helps to increase GSH pools. In addition, at least under conditions of serine deprivation, p53 can also promote GSH synthesis directly (Maddocks et al. 2013), further increasing the ability of stressed cells to detoxify ROS. At the mitochondria, p53 activities that promote increased mitochondrial quality-control mechanisms, better electron transport chain function, and enhanced mitochondrial integrity also act to limit mitochondrial ROS levels (Okamura et al. 1999; Vahsen et al. 2004; Matoba et al. 2006; Stambolsky et al. 2006; Kitamura et al. 2011). More directly, it has been shown in hematopoietic stem cells (HSCs) that increased ROS stress activates 
T.J. Humpton and K.H. Vousden

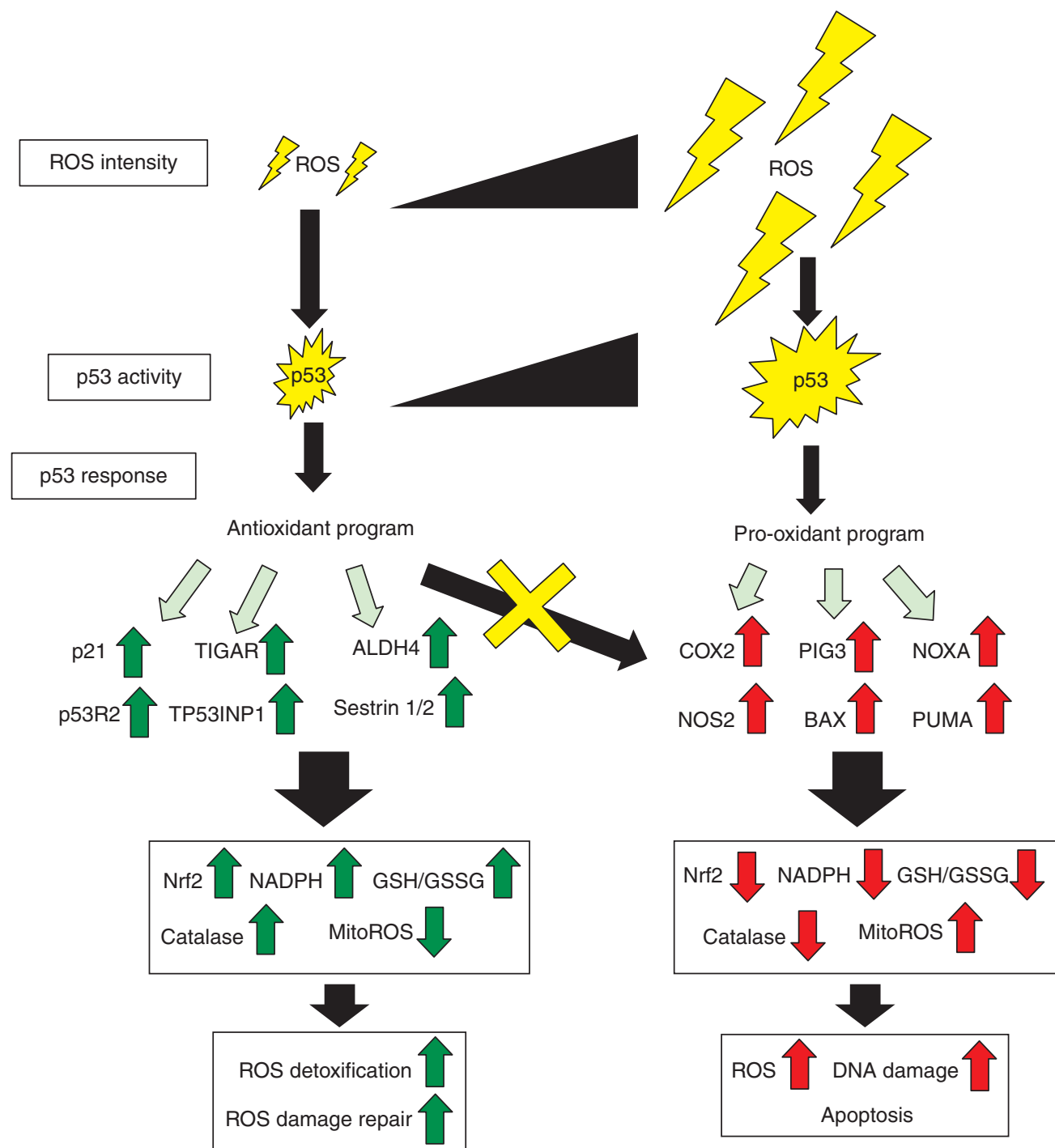

Figure 4. p53 alters metabolism in response to reactive oxygen species (ROS) stress. Depending on the intensity of ROS stress, p53 can direct alternative antioxidant and pro-oxidant programs to support either cell survival or death. Low levels of ROS promote p53-mediated induction of several antioxidant effectors that, in turn, facilitate ROS detoxification and cell survival. High ROS stress, in contrast, causes p53 to engage pro-oxidant pathways to stimulate greater ROS accumulation, DNA damage, and apoptosis. TIGAR, Tp53-induced glycolysis and apoptosis regulator; ALDH, aldehyde dehydrogenase; mitoROS, mitochondrial reactive oxygen species.

the ROS sensor thioredoxin-interacting protein (TXNIP) (Jung et al. 2013). Activated TXNIP inhibits the MDM2-p53 interaction and consequently increases p53 transcriptional activity to support p53-directed antioxidant programs (Jung et al. 2013). Although speculative, the mi- tochondrial respiration-promoting activities of p53 may depend on the protective antioxidant function of p53 to help balance resultant mitochondrial ROS production. It also seems plausible that the enhanced glycolysis seen following p53 loss in cancer cells may be, in part, a mech- 
anism to avoid mitochondrial ROS production when the antioxidant activities of p53 are lost. Further research will be required to address this possibility.

At the transcriptional level, induction of p53 following transient ROS stress promotes the expression of many antioxidant genes, including aldehyde dehydrogenase 4 (ALDH4), the Sestrin family of proteins, p53R2, p21, and tumor protein $\mathrm{p} 53$-inducible nuclear protein 1 (TP53INP1) (Tan et al. 1999; Yoon et al. 2004; Bourdon et al. 2007; Cano et al. 2009; Budanov 2011). These redox regulators suppress modest increases in cellular ROS levels and promote detoxification. Augmented levels of p53R2, for example, have been shown to enhance catalase antioxidant activity and protect against ROS (Kang et al. 2012). At the same time, p53-induced p21 can enhance the activation of the Nrf2 antioxidant transcriptional network (Chen et al. 2009, 2012; Villeneuve et al. 2009; Jaramillo and Zhang 2013). In addition, p53 can inhibit the levels of several pro-oxidant genes, including nitric oxide synthase 2 (NOS2) and cyclooxygenase 2 (COX2) (Ambs et al. 1998; Subbaramaiah et al. 1999). The net result of these programs is to reduce the cellular redox state and detoxify ROS.

The apoptotic arm of p53 activity complicates the relationship between p53 and ROS control. When stress levels within a cell are high or persistent, the activity of p53 shifts to promote increased ROS and cell death (Fig. 4). It has been shown, for example, that p53 can directly inhibit the function of glucose-6-phosphate dehydrogenase (G6PDH), the first and rate-limiting step in the $\mathrm{PPP}$, and so limit NADPH production through this pathway (Fig. 2) (Jiang et al. 2011). Furthermore, the inhibition of malic enzyme by p53 described above can also limit NADPH productionand so increase ROS (Jiang et al. 2013). p53 can also suppress the Nrf2 antioxidant network and promote transcription of pro-oxidant genes to further increase ROS levels (Hammond and Giaccia 2005; Liu et al. 2005; Faraonio et al. 2006; Tu et al. 2009; Chen et al. 2012; Kang et al. 2012). As a counterpoint to the positive effect of p53R2 on catalase activity, for example, it has been shown that the combination of high levels of p53 protein and greater p53-mediated transcription of the pro-oxidant gene p53-inducible gene 3 (PIG3) inhibit catalase activity, again increasing ROS levels (Kang et al. 2012). Thus, the outcome of p53-mediated control over ROS depends directly on the intensity and duration of the stress.

\section{RAREFIED AIR: HYPOXIA AND p53}

In a manner similar to ROS and nutrient stress, decreased oxygen availability (hypoxia) can also engage p53 (Koumenis et al. 2001; Schmid et al. 2004; Hammond and Giaccia 2006; Sermeus and Michiels 2011). As with the p53 ROS response, the nature of $\mathrm{p} 53$ activity during hypoxia depends on the severity of the oxygen deficit, the cell type involved, and the duration of the hypoxic episode. Although transient or mild hypoxia generally promotes prosurvival functions of the p53 response, severe or extended hypoxia activates p53-mediated apoptosis (Fig. 5) (Hammond et al. 2002; Fei et al. 2004; Kim et al. 2004; Li et al. 2004; Feng et al. 2011).

In general, the cellular response to hypoxia is regulated by the activity of the HIF-1 transcription factor complex. HIF-1 is a heterodimer composed of a HIF-1 $\alpha$ subunit and the HIF-1 $\beta$ (or ARNT) subunit. Although both subunits are constitutively expressed, the stability of the HIF- $1 \alpha$ subunit is exquisitely sensitive to the cytoplasmic oxygen concentration due to an oxygen-dependent degradation domain (ODD) found within the protein. Under normal oxygen tension, the ODD ensures that HIF$1 \alpha$ is immediately degraded. However, when the oxygen level falls or the ODD is inhibited through other means, HIF- $1 \alpha$ is stabilized and forms an active transcription complex with HIF-1 $\beta$ (Schmid et al. 2004; Weinberg 2007). The stabilized HIF complex can then promote the transcription of genes containing a hypoxia response element within their promoter region (Weidemann and Johnson 2008).

Under conditions of moderate hypoxia, HIF-1 activity is high and p53 protein levels are largely un-induced. Perhaps as a consequence, in this oxygen regime the activity of 
T.J. Humpton and K.H. Vousden

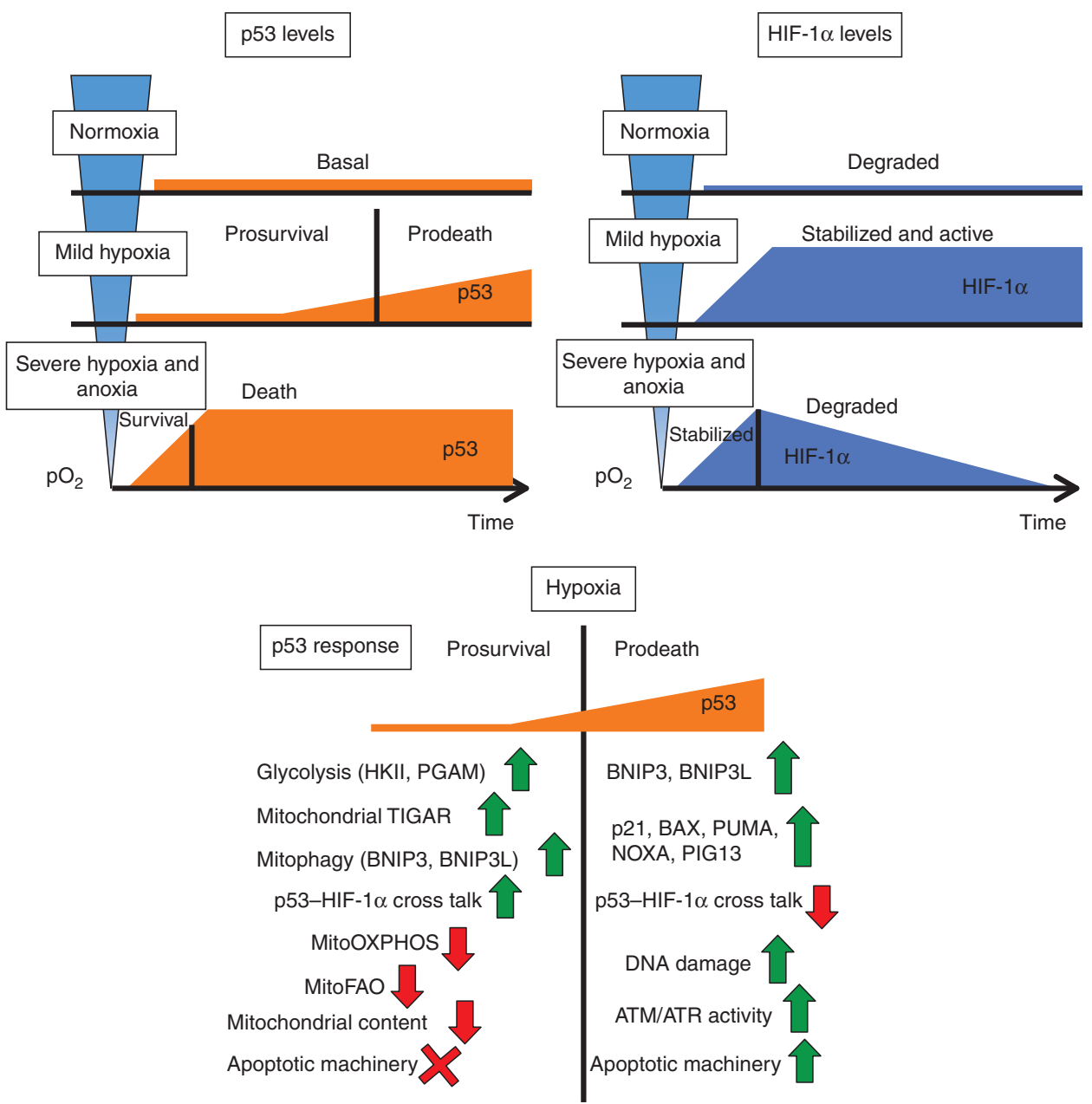

Figure 5. The duration and severity of hypoxia contribute to differential p53-mediated outcomes for cell survival during hypoxic stress. Mild and/or transient hypoxia tends to engage prosurvival activities of the p53 protein to support increased glycolysis and decreased mitochondrial activity in concert with HIF- $1 \alpha$-mediated prosurvival pathways. Extended or severe hypoxia uncouples HIF-1 $\alpha$ and p53 functions and promotes the p53-mediated induction of apoptosis. HKII, Hexokinase II; PGAM, phosphoglycerate mutase; TIGAR, Tp53-induced glycolysis and apoptosis regulator; OXPHOS, oxidative phosphorylation.

p53 is constrained and tends to support cell survival (Alarcón et al. 1999; Li et al. 2004; Feng et al. 2011). Under more severe hypoxia and after total loss of $\mathrm{O}_{2}$ (anoxia), however, p53 is strongly induced, HIF- $1 \alpha$ levels generally decrease, and canonical tumor-suppressive proapoptotic activities of p53 are engaged (Fig. 5) (Hammond et al. 2002; Fei et al. 2004; Kim et al. 2004; Wang et al. 2013). Although the cross talk between HIF-1 and p53 is important in defining the cellular response to gradations of hypoxia (An et al. 1998; Alarcón et al. 1999), given the lack of strong correlation between HIF-1 induction and overt p53 increase, it seems plausible that the induction of $\mathrm{p} 53$ for apoptosis in very low oxygen is independent of HIF-1 activity per se. Possibly, apoptotic p53 responds to DNA damage and other consequences of reduced oxygen levels rather than to the lowered oxygen tension directly (Hammond et al. 2002; Pan et al. 2004). 
Under the less extreme case of mild and/or transient hypoxia, p53 acts via many of the same levers used during metabolic stress to promote cell survival (Fig. 5). However, it is important to note that the way in which p53 alters metabolism in response to hypoxia tends to be opposite to p53 control during nutrient starvation. In hypoxia, p53 promotes expression of proglycolytic enzymes including hexokinase II (HKII) and PGAM to enhance carbohydrate flux through glycolysis (Mathupala et al. 1997, 2006; Ruiz-Lozano et al. 1999). Although these activities are at odds with the antiglycolytic programs implemented by p53 during nutrient starvation, the disparities can be reconciled by considering the situation-specific requirements for the p53 response in each case. Under hypoxia, oxygen-requiring and oxygen-producing activities, including mitochondrial respiration and FAO, must be minimized. Alternative pathways to maintain energy stores are required to make up the difference. As such, p53-mediated engagement of HKII and PGAM, as well as other activities to promote glycolysis, represent an important cornerstone of the p53-mediated hypoxic response. Under hypoxia, p53 increases HKII expression directly. At the same time, TIGAR localizes to the mitochondria, interacts with HKII, and promotes greater HKII activity-diminishing mitochondrial ROS production (Cheung et al. 2012).

Also acting on the mitochondria, the p53 and HIF- $1 \alpha$-mediated transcriptional induction of BNIP3 and NIX, two mitochondrial proteins that direct mitochondrial clearance (mitophagy), promotes active suppression of mitochondrial content and diminished mitochondrial activity in hypoxic cells (Guo et al. 2001; Sowter et al. 2001; Bellot et al. 2009; Zhang and Ney 2009). At the same time, p53 can limit mitochondrial biogenesis by inhibiting PGC- $1 \alpha$ and $\beta$ (Sahin et al. 2011). Although not a p53-specific outcome, the lack of oxygen encountered in hypoxia also inhibits mitochondrial FAO because of the inability of NADH and $\mathrm{FADH}_{2}$ to be oxidized as required in the first step of the process. Both directly and indirectly, these programs shunt metabolites away from oxygen-requiring processes and toward glycol- ysis to enable cells to generate sufficient ATP and metabolic intermediates to survive hypoxia. However, because both NIX and BNIP3 can function as apoptotic mediators, under severe hypoxia, the function of these mitophagy proteins can shift to implement p53-directed cell death (Fei et al. 2004; Wang et al. 2013).

Finally, the transition from hypoxia back to normal oxygen tension (normoxia) can also be fraught if it occurs too rapidly. The rapid oxygen binge that occurs during reperfusion of the heart after an ischemic event, for example, can induce high levels of ROS, activate p53, and cause apoptosis (Fliss and Gattinger 1996; Yellon and Hausenloy 2007). In mice, it has been shown that such ischemia-reperfusion episodes cause apoptosis in cardiomyocytes via both p53 and TIGAR-dependent mechanisms and that cell death can be avoided through inhibition of p53 (Shizukuda et al. 2005; Matsusaka et al. 2006; Kimata et al. 2010; Hoshino et al. 2012). Thus, as with nutrient excess conditions, it seems likely that the induction of p53 during reperfusion plays an important role in determining cell fate when oxygen is restored to a previously hypoxic tissue environment.

\section{CONCLUDING REMARKS}

Although the p53 protein has largely been defined over its history as a tumor suppressor, an underappreciated yet equally important role for p53 exists within the management of cellular metabolism during nutrient and oxygen stress. Perturbations in metabolite availability, for example, are rapidly relayed to p53 through its tight interaction with key nutrientsensing pathways of the cell including AMPK, the mTOR-signaling network, eIF $2 \alpha$, and mitochondria. During starvation, these front-line sensors transiently engage moderate (sublethal) levels of p53 activity that augment cell-survival pathways, inhibit unnecessary growth, and promote efficient nutrient utilization and conservation. Similarly, during transient hypoxia, direct interactions and signaling cross talk between p53 and HIF-1 facilitate redirection of cellular metabolism toward energy generation 
through nonoxidative means and the suppression of ROS generation-promoting cell survival. In each case, however, if deleterious conditions become too severe or persistent, p53 function can pivot to orchestrate the death of damaged cells.

At first glance, the role of p53 in directing metabolism in response to stress can appear removed from its canonical activities limiting tumorigenesis. However, when the utility of p53 is considered across its evolutionary history, these seemingly disparate roles can be reconciled as related features of the same underlying protective role for $\mathrm{p} 53$. The $\mathrm{p} 53$ protein (and its closely related family members, p63 and p73) evolved in simple organisms that did not require tumor surveillance (Allocati et al. 2012). Therefore, it is likely that the original function of the p53 family was as general stress sensors whose remit was to protect the viability of a cell as well as the integrity of its genome within the germline. As such, the p53 family would be required to sense, respond to, and ultimately manage stochastic environmental stressors for as long as possible without killing the cell. At the same time, once genome integrity was breached, p53 could function to recognize the event and orchestrate containment of the compromised cell and its defective DNAthrough its death - to preserve the genomic integrity of the larger organism. From this perspective, p53-directed tumor suppression can be rationalized as an extension of primitive p53 stress-response activities to the unique emergent problem of tumorigenesis in higher organisms. In this model, premalignant cells initially engage p53 and induce its cell repair and survival functions. The prevention and repair of damage through these pathways would help to limit oncogenic progression. However, sustained oncogenic stress would overwhelm these processes and tilt p53 activity into its tumor-suppressive cell-elimination role. In this view, then, the actions of p53 to control metabolism in response to nutrient or oxygen stress as described here and those necessary to suppress tumors are interrelated facets of the same primitive stress tolerance and guardian functions of the p53 family.

\section{ACKNOWLEDGMENTS}

This work is supported by Cancer Research UK Grant C596/A10419 and European Research Council (ERC) Grant 322842-METABOp53.

\section{REFERENCES}

*Reference is also in this collection.

Alarcón R, Koumenis C, Geyer RK, Maki CG, Giaccia AJ. 1999. Hypoxia induces p53 accumulation through MDM2 down-regulation and inhibition of E6-mediated degradation. Cancer Res 59: 6046-6051.

Allocati N, Di Ilio C, De Laurenzi V. 2012. p63/p73 in the control of cell cycle and cell death. Exp Cell Res 318: $1285-1290$.

Ambs S, Ogunfusika MO, Merriam WG, Bennett WP, Billiar TR, Harris CC. 1998. Up-regulation of inducible nitric oxide synthase expression in cancer-prone p53 knockout mice. Proc Natl Acad Sci 95: 8823-8828.

An WG, Kanekal M, Simon MC, Maltepe E, Blagosklonny MV, Neckers LM. 1998. Stabilization of wild-type p53 by hypoxia-inducible factor $1 \alpha$. Nature 392: 405-408.

Armata HL, Golebiowski D, Jung DY, Ko HJ, Kim JK, Sluss HK. 2010. Requirement of the ATM/p53 tumor suppressor pathway for glucose homeostasis. Mol Cell Biol 30: 5787-5794.

Assaily W, Rubinger DA, Wheaton K, Lin Y, Ma W, Xuan W, Brown-Endres L, Tsuchihara K, Mak TW, Benchimol S. 2011. ROS-mediated p53 induction of Lpin1 regulates fatty acid oxidation in response to nutritional stress. Mol Cell 44: 491-501.

Bellot G, Garcia-Medina R, Gounon P, Chiche J, Roux D, Pouysségur J, Mazure NM. 2009. Hypoxia-induced autophagy is mediated through hypoxia-inducible factor induction of BNIP3 and BNIP3L via their BH3 domains. Mol Cell Biol 29: 2570-2581.

Bensaad K, Tsuruta A, Selak MA, Vidal MNC, Nakano K, Bartrons R, Gottlieb E, Vousden KH. 2006. TIGAR, a p53-inducible regulator of glycolysis and apoptosis. Cell 126: $107-120$.

Boidot R, Végran F, Meulle A, Le Breton A, Dessy C, Sonveaux P, Lizard-Nacol S, Feron O. 2012. Regulation of monocarboxylate transporter MCT1 expression by p53 mediates inward and outward lactate fluxes in tumors. Cancer Res 72: 939-948.

Bois-Joyeux B, Chanez M, Peret J. 1987. Changes in rat hepatic fructose 2,6-bisphosphate and 6-phosphofructo-2-kinase/fructose 2,6-bisphosphatase activity during three days of consumption of a high protein diet or starvation. Diabete Metab 13: 543-548.

Bourdon A, Minai L, Serre V, Jais JP, Sarzi E, Aubert S, Chrétien D, de Lonlay P, Paquis-Flucklinger V, Arakawa $\mathrm{H}$, et al. 2007. Mutation of RRM2B, encoding p53controlled ribonucleotide reductase (p53R2), causes severe mitochondrial DNA depletion. Nat Genet 39: 776-780.

Bowtell JL, Bruce M. 2002. Glutamine: An anaplerotic precursor. Nutrition 18: 222-224. 
Budanov AV. 2011. Stress-responsive sestrins link p53 with redox regulation and mammalian target of rapamycin signaling. Antioxid Redox Signal 15: 1679-1690.

Burgdorf KS, Grarup N, Justesen JM, Harder MN, Witte DR, Jørgensen T, Sandbæk A, Lauritzen T, MadsbadS, Hansen T, et al. 2011. Studies of the association of Arg72Pro of tumor suppressor protein $\mathrm{p} 53$ with type 2 diabetes in a combined analysis of 55,521 Europeans. PLoS ONE 6: 4-9.

Cano CE, Gommeaux J, Pietri S, Culcasi M, Garcia S, Seux M, Barelier S, Vasseur S, Spoto RP, Pébusque MJ, et al. 2009. Tumor protein 53-induced nuclear protein 1 is a major mediator of p53 antioxidant function. Cancer Res 69: $219-226$.

Chen W, Sun Z, Wang XJ, Jiang T, Huang Z, Fang D, Zhang DD. 2009. Direct interaction between Nrf2 and $\mathrm{p} 21^{\mathrm{Cip} 1 / \mathrm{WAF} 1}$ upregulates the Nrf2-mediated antioxidant response. Mol Cell 34: 663-673.

Chen W, Jiang T, Wang H, Tao S, Lau A, Fang D, Zhang DD. 2012. Does Nrf2 contribute to p53-mediated control of cell survival and death? Antioxid Redox Signal 17: 16701675.

Cheung EC, Ludwig RL, Vousden KH. 2012. Mitochondrial localization of TIGAR under hypoxia stimulates HK2 and lowers ROS and cell death. Proc Natl Acad Sci 109: 20491-20496.

Circu ML, Aw TY. 2010. Reactive oxygen species, cellular redox systems, and apoptosis. Free Radic Biol Med 48: 749-762.

Claus TH, Nyfeler F, Muenkel HA, Burns MG, Pilkis SJ. 1984. Changes in fructose-2,6-bisphosphate levels after glucose loading of starved rats. Biochem Biophys Res Commun 122: 529-534.

Clemens MJ. 2001. Initiation factor eIF2 $\alpha$ phosphorylation in stress responses and apoptosis. Prog Mol Subcell Biol 27: $57-89$.

Contractor T, Harris CR. 2012. p53 negatively regulates transcription of the pyruvate dehydrogenase kinase Pdk2. Cancer Res 72: 560-567.

D'Autréaux B, Toledano MB. 2007. ROS as signalling molecules: Mechanisms that generate specificity in ROS homeostasis. Nat Rev Mol Cell Biol 8: 813-824.

Derdak Z, Lang CH, Villegas KA, Tong M, Mark NM, De La Monte SM, Wands JR. 2011. Activation of p53 enhances apoptosis and insulin resistance in a rat model of alcoholic liver disease. J Hepatol 54: 164-172.

Dieuaide M, Brouquisse R, Pradet A, Raymond P. 1992. Increased fatty acid $\beta$-oxidation after glucose starvation in maize root tips. Plant Physiol 99: 595-600.

Dröge W. 2002. Free radicals in the physiological control of cell function. Physiol Rev 82: 47-95.

Faraonio R, Vergara P, Di Marzo D, Pierantoni MG, Napolitano M, Russo T, Cimino F. 2006. p53 suppresses the Nrf2-dependent transcription of antioxidant response genes. J Biol Chem 281: 39776-39784.

Fei P, Wang W, Kim S, Wang S, Burns TF, Sax JK, Buzzai M, Dicker DT, McKenna WG, Bernhard EJ, et al. 2004 Bnip3L is induced by p53 under hypoxia, and its knockdown promotes tumor growth. Cancer Cell 6: 597-609.

Feng Z, Levine AJ. 2010. The regulation of energy metabolism and the IGF- $1 / \mathrm{mTOR}$ pathways by the $\mathrm{p} 53$ protein. Trends Cell Biol 20: 427-434.
Feng J, Tamaskovic R, Yang Z, Brazil DP, Merlo A, Hess D, Hemmings BA. 2004. Stabilization of Mdm2 via decreased ubiquitination is mediated by protein kinase B/Akt-dependent phosphorylation. J Biol Chem 279: 35510-35517.

Feng Z, Hu W, De Stanchina E, Teresky AK, Jin S, Lowe S, Levine AJ. 2007. The regulation of AMPK $\beta 1$, TSC2, and PTEN expression by p53: Stress, cell and tissue specificity, and the role of these gene products in modulating the IGF-1-AKT-mTOR pathways. Cancer Res 67: 3043-3053.

Feng X, Liu X, Zhang W, Xiao W. 2011. p53 directly suppresses BNIP3 expression to protect against hypoxia-induced cell death. EMBO J 30: 3397-3415.

Fiordaliso F, Leri A, Cesselli D, Limana F, Safai B, NadalGinard B, Anversa P, Kajstura J. 2001. Hyperglycemia activates $\mathrm{p} 53$ and p53-regulated genes leading to myocyte cell death. Diabetes 50: 2363-2375.

Fliss H, Gattinger D. 1996. Apoptosis in ischemic and reperfused rat myocardium. Circ Res 79: 949-956.

Frisardi V, Solfrizzi V, Seripa D, Capurso C, Santamato A, Sancarlo D, Vendemiale G, Pilotto A, Panza F. 2010. Metabolic-cognitive syndrome: A cross-talk between metabolic syndrome and Alzheimer's disease. Ageing Res Rev 9: 399-417.

Garufi A, D’Orazi G. 2014. High glucose dephosphorylates serine 46 and inhibits p53 apoptotic activity. J Exp Clin Cancer Res 33: 79.

Gaulton KJ, Willer CJ, Li Y, Scott LJ, Conneely KN, Jackson AU, Duren WL, Chines PS, Narisu N, Bonnycastle LL, et al. 2008. Comprehensive association study of type 2 diabetes and related quantitative traits with 222 candidate genes. Diabetes 57: 3136-3144.

Goldstein I, Rotter V. 2012. Regulation of lipid metabolism by p53-Fighting two villains with one sword. Trends Endocrinol Metab 23: 567-575.

Goldstein I, Yizhak K, Madar S, Goldfinger N, Ruppin E, Rotter V. 2013. p53 promotes the expression of gluconeogenesis-related genes and enhances hepatic glucose production. Cancer Metab 1: 9.

Gomes LC, Di Benedetto G, Scorrano L. 2011. During autophagy mitochondria elongate, are spared from degradation and sustain cell viability. Nat Cell Biol 13: 589598.

Guo K, Searfoss G, Krolikowski D, Pagnoni M, Franks C, Clark K, Yu KT, Jaye M, Ivashchenko Y. 2001. Hypoxia induces the expression of the pro-apoptotic gene BNIP3. Cell Death Differ 8: 367-376.

Hammond EM, Giaccia AJ. 2005. The role of p53 in hypoxia-induced apoptosis. Biochem Biophys Res Commun 331: 718-725.

Hammond EM, Giaccia AJ. 2006. Hypoxia-inducible factor1 and p53: Friends, acquaintances, or strangers? Clin Cancer Res 12: 5007-5009.

Hammond EM, Denko NC, Dorie MJ, Abraham RT, Giaccia AJ. 2002. Hypoxia links ATR and p53 through replication arrest. Mol Cell Biol 22: 1834-1843.

Hardie DG. 2011. AMP-activated protein kinase-an energy sensor that regulates all aspects of cell function. Genes Dev 25: 1895-1908. 
T.J. Humpton and K.H. Vousden

Hardie DG, Ross FA, Hawley SA. 2012. AMPK: A nutrient and energy sensor that maintains energy homeostasis. Nat Rev Mol Cell Biol 13: 251-262.

Hay N, Sonenberg N. 2004. Upstream and downstream of mTOR. Genes Dev 18: 1926-1945.

Horn HF, Vousden KH. 2007. Coping with stress: Multiple ways to activate p53. Oncogene 26: 1306-1316.

Hoshino A, Matoba S, Iwai-Kanai E, Nakamura H, Kimata M, Nakaoka M, Katamura M, Okawa Y, Ariyoshi M, Mita Y, et al. 2012. p53-TIGAR axis attenuates mitophagy to exacerbate cardiac damage after ischemia. J Mol Cell Cardiol 52: 175-184.

$\mathrm{Hu}$ W, Zhang C, Wu R, Sun Y, Levine A, Feng Z. 2010. Glutaminase 2, a novel p53 target gene regulating energy metabolism and antioxidant function. Proc Natl Acad Sci 107: $7455-7460$.

Huang PL. 2009. A comprehensive definition for metabolic syndrome. Dis Model Mech 2: 231-237.

Imamura K, Ogura T, Kishimoto A, Kaminishi M, Esumi H. 2001. Cell cycle regulation via p53 phosphorylation by a $5^{\prime}$-AMP activated protein kinase activator, 5-aminoimidazole- 4-carboxamide-1- $\beta$-D-ribofuranoside, in a human hepatocellular carcinoma cell line. Biochem Biophys Res Commun 287: 562-567.

Jaramillo M, Zhang D. 2013. The emerging role of the Nrf2Keap1 signaling pathway in cancer. Genes Dev 27: 21792191.

Jiang P, Du W, Wang X, Mancuso A, Gao X, Wu M, Yang X. 2011. p53 regulates biosynthesis through direct inactivation of glucose-6-phosphate dehydrogenase. Nat Cell Biol 13: $310-316$.

Jiang P, Du W, Mancuso A, Wellen KE, Yang X. 2013. Reciprocal regulation of p53 and malic enzymes modulates metabolism and senescence. Nature 493: 689-693.

Jiang D, LaGory EL, Kenzelmann Brož D, Bieging KT, Brady CA, Link N, Abrams JM, Giaccia AJ, Attardi LD. 2015. Analysis of p53 transactivation domain mutants reveals Acad11 as a metabolic target important for p53 pro-survival function. Cell Rep 10: 1096-1109.

Jones RG, Plas DR, Kubek S, Buzzai M, Mu J, Xu Y, Birnbaum MJ, Thompson CB. 2005. AMP-activated protein kinase induces a p53-dependent metabolic checkpoint. Mol Cell 18: 283-293.

Jung H, Kim MJ, Kim DO, Kim WS, Yoon SJ, Park YJ, Yoon SR, Kim TD, Suh HW, Yun S, et al. 2013. TXNIP maintains the hematopoietic cell pool by switching the function of p53 under oxidative stress. Cell Metab 18: 75-85.

Kang MY, Kim H-B, Piao C, Lee KH, Hyun JW, Chang I-Y, You HJ. 2012. The critical role of catalase in prooxidant and antioxidant function of p53. Cell Death Differ 20: 117-129.

Kaur J. 2014. A comprehensive review on metabolic syndrome. Cardiol Res Pract 2014: 943162.

Kawauchi K, Araki K, Tobiume K, Tanaka N. 2008. p53 regulates glucose metabolism through an IKK-NF- $\mathrm{B}$ pathway and inhibits cell transformation. Nat Cell Biol 10: $611-618$.

Kim JY, Ahn HJ, Ryu JH, Suk K, Park JH. 2004. BH3-only protein Noxa is a mediator of hypoxic cell death induced by hypoxia-inducible factor $1 \alpha$. J Exp Med 199: 113-124.
Kimata M, Matoba S, Iwai-Kanai E, Nakamura H, Hoshino A, Nakaoka M, Katamura M, Okawa Y, Mita Y, Okigaki M, et al. 2010. p53 and TIGAR regulate cardiac myocyte energy homeostasis under hypoxic stress. Am J Physiol Heart Circ Physiol 299: H1908-H1916.

Kitamura N, Nakamura Y, Miyamoto Y, Miyamoto T, Kabu K, Yoshida M, Futamura M, Ichinose S, Arakawa H. 2011. Mieap, a p53-inducible protein, controls mitochondrial quality by repairing or eliminating unhealthy mitochondria. PLOS ONE 6: e16060.

Kondoh H, Lleonart ME, Gil J, Wang J, Degan P, Peters G Martinez D, Carnero A, Beach D. 2005. Glycolytic enzymes can modulate cellular life span. Cancer Res 65: 177- 185 .

Koumenis C, Alarcon R, Hammond E, Sutphin P, Hoffman W, Murphy M, Derr J, Taya Y, Lowe SW, Kastan M, et al. 2001. Regulation of p53 by hypoxia: Dissociation of transcriptional repression and apoptosis from p53-dependent transactivation. Mol Cell Biol 21: 1297-1310.

Kurland IJ, Pilkis SJ. 1995. Covalent control of 6-phosphofructo-2-kinase/fructose-2,6-bisphosphatase: Insights into autoregulation of a bifunctional enzyme. Protein Sci 4: 1023-1037.

Laplante M, Sabatini DM. 2012. MTOR signaling in growth control and disease. Cell 149: 274-293.

Lau ATY, Wang Y, Chiu JF. 2008. Reactive oxygen species: Current knowledge and applications in cancer research and therapeutic. J Cell Biochem 104: 657-667.

Le A, Lane AN, Hamaker M, Bose S, Gouw A, Barbi J, Tsukamoto T, Rojas CJ, Slusher BS, Zhang H, et al. 2012. Glucose-independent glutamine metabolism via TCA cycling for proliferation and survival in B cells. Cell Metab 15: 110-121.

Lee CH, Inoki K, Karbowniczek M, Petroulakis E, Sonenberg N, Henske EP, Guan KL. 2007. Constitutive mTOR activation in TSC mutants sensitizes cells to energy starvation and genomic damage via p53. EMBO J 26: 4812-4823.

Levine B, Kroemer G. 2008. Autophagy in the pathogenesis of disease. Cell 132: 27-42.

Li H, Jogl G. 2009. Structural and biochemical studies of TIGAR (TP53-induced glycolysis and apoptosis regulator). J Biol Chem 284: 1748-1754.

Li J, Zhang X, Sejas DP, Bagby GC, Pang Q. 2004. Hypoxiainduced nucleophosmin protects cell death through inhibition of p53. J Biol Chem 279: 41275-41279.

Liu Z, Lu H, Shi H, Du Y, Yu J, Gu S, Chen X, Ke JL, Hu CAA. 2005. PUMA overexpression induces reactive oxygen species generation and proteasome-mediated stathmin degradation in colorectal cancer cells. Cancer Res 65: 1647-1654.

Liu B, Chen Y, St. Clair DK. 2008. ROS and p53: Aversatile partnership. Free Radic Biol Med 44: 1529-1535.

Liu Y, He Y, Jin A, Tikunov AP, Zhou L, Tollini L, Leslie P, Kim TH, Li LO, Coleman R, et al. 2014. Ribosomal protein-Mdm2-p53 pathway coordinates nutrient stress with lipid metabolism by regulating MCD and promoting fatty acid oxidation. Proc Natl Acad Sci 111: E2414E2422.

Maddocks ODK, Berkers CR, Mason SM, Zheng L, Blyth K, Gottlieb E, Vousden KH. 2013. Serine starvation induces 
stress and p53-dependent metabolic remodelling in cancer cells. Nature 493: 542-546.

Maiuri MC, Galluzzi L, Morselli E, Kepp O, Malik SA, Kroemer G. 2010. Autophagy regulation by p53. Curr Opin Cell Biol 22: 181-185.

Martin HL, Teismann P. 2009. Glutathione-A review on its role and significance in Parkinson's disease. FASEB J 23: 3263-3272.

Mathupala SP, Heese C, Pedersen PL. 1997. Glucose catabolism in cancer cells. The type II hexokinase promoter contains functionally active response elements for the tumor suppressor p53. J Biol Chem 272: 2277622780 .

Mathupala SP, Ko YH, Pedersen PL. 2006. Hexokinase II: Cancer's double-edged sword acting as both facilitator and gatekeeper of malignancy when bound to mitochondria. Oncogene 25: 4777-4786.

Matoba S, Kang JG, Patino WD, Wragg A, Boehm M, Gavrilova O, Hurley PJ, Bunz F, Hwang PM. 2006. p53 regulates mitochondrial respiration. Science 312: 1650 1653.

Matsusaka H, Ide T, Matsushima S, Ikeuchi M, Kubota T, Sunagawa K, Kinugawa S, Tsutsui H. 2006. Targeted deletion of p53 prevents cardiac rupture after myocardial infarction in mice. Cardiovasc Res 70: 457-465.

Mayo LD, Donner DB. 2001. A phosphatidylinositol 3-kinase/Akt pathway promotes translocation of $\mathrm{Mdm} 2$ from the cytoplasm to the nucleus. Proc Natl Acad Sci 98: $11598-11603$.

Miceli AP, Saporita AJ, Weber JD. 2012. Hypergrowth mTORC1 signals translationally activate the ARF tumor suppressor checkpoint. Mol Cell Biol 32: 348-364.

Minamino T, Orimo M, Shimizu I, Kunieda T, Yokoyama M, Ito T, Nojima A, Nabetani A, Oike Y, Matsubara H, et al. 2009. A crucial role for adipose tissue p53 in the regulation of insulin resistance. Nat Med 15: 1082-1087.

Mor I, Cheung EC, Vousden KH. 2011. Control of glycolysis through regulation of PFK1: Old friends and recent additions. Cold Spring Harb Symp Quant Biol 76: 211-216.

Moremen KW, Tiemeyer M, Nairn AV. 2012. Vertebrate protein glycosylation: Diversity, synthesis and function. Nat Rev Mol Cell Biol 13: 448-462.

Morselli E, Galluzzi L, Kepp O, Vicencio JM, Criollo A, Maiuri MC, Kroemer G. 2009. Anti- and pro-tumor functions of autophagy. Biochim Biophys Acta Mol Cell Res 1793: 1524-1532.

Mungamuri SK, Yang X, Thor AD, Somasundaram K. 2006. Survival signaling by Notch1: Mammalian target of rapamycin (mTOR)-dependent inhibition of p53. Cancer Res 66: 4715-4724.

Ogawara Y, Kishishita S, Obata T, Isazawa Y, Suzuki T, Tanaka K, Masuyama N, Gotoh Y. 2002. Akt enhances Mdm2mediated ubiquitination and degradation of p53. J Biol Chem 277: 21843-21850.

Okamura S, Ng CC, Koyama K, Takei Y, Arakawa H, Monden M, Nakamura Y. 1999. Identification of seven genes regulated by wild-type p53 in a colon cancer cell line carrying a well-controlled wild-type p53 expression system. Oncol Res 11: 281-285.
Okorokov AL, Milner J. 1999. An ATP/ADP-dependent molecular switch regulates the stability of p53-DNA complexes. Mol Cell Biol 19: 7501-7510.

Okoshi R, Ozaki T, Yamamoto H, Ando K, Koida N, Ono S, Koda T, Kamijo T, Nakagawara A, Kizaki H. 2008. Activation of AMP-activated protein kinase induces p53-dependent apoptotic cell death in response to energetic stress. J Biol Chem 283: 3979-3987.

Ou Y, Wang SJ, Jiang L, Zheng B, Gu W. 2015. p53 proteinmediated regulation of phosphoglycerate dehydrogenase (PHGDH) is crucial for the apoptotic response upon serine starvation. J Biol Chem 290: 457-466.

Pan Y, Oprysko PR, Asham AM, Koch CJ, Simon MC. 2004. p53 cannot be induced by hypoxia alone but responds to the hypoxic microenvironment. Oncogene 23: 4975-4983.

Peterson TR, Sengupta SS, Harris TE, Carmack AE, Kang SA, Balderas E, Guertin DA, Madden KL, Carpenter AE, Finck BN, et al. 2011. MTOR complex 1 regulates lipin 1 localization to control the SREBP pathway. Cell 146: 408-420.

Polyak K, Xia Y, Zweier JL, Kinzler KW, Vogelstein B. 1997. A model for p53-induced apoptosis. Nature 389: 300-305.

Rabinowitz JD, White E. 2010. Autophagy and metabolism. Science 330: 1344-1348.

Reid MA, Wang WI, Rosales KR, Welliver MX, Pan M, Kong M. 2013. The B55 $\alpha$ subunit of PP2A drives a p53-dependent metabolic adaptation to glutamine deprivation. $\mathrm{Mol}$ Cell 50: 200-211.

Ruiz-Lozano P, Hixon ML, Wagner MW, Flores AI, Ikawa S, Baldwin AS, Chien KR, Gualberto A. 1999. p53 is a transcriptional activator of the muscle-specific phosphoglycerate mutase gene and contributes in vivo to the control of its cardiac expression. Cell Growth Differ 10: 295-306.

Sablina AA, Budanov AV, Ilyinskaya GV, Agapova LS, Kravchenko JE, Chumakov PM. 2005. The antioxidant function of the p53 tumor suppressor. Nat Med 11: 1306-1313.

Sahin E, Colla S, Liesa M, Moslehi J, Müller FL, Guo M, Cooper M, Kotton D, Fabian AJ, Walkey C, et al. 2011. Telomere dysfunction induces metabolic and mitochondrial compromise. Nature 470: 359-365.

Santos CR, Schulze A. 2012. Lipid metabolism in cancer. FEBS J 279: 2610-2623.

Saqcena M, Mukhopadhyay S, Hosny C, Alhamed A, Chatterjee A, Foster D. 2014. Blocking anaplerotic entry of glutamine into the TCA cycle sensitizes K-Ras mutant cancer cells to cytotoxic drugs. Oncogene 34: 1-9.

Scherz-Shouval R, Weidberg H, Gonen C, Wilder S, Elazar Z, Oren M. 2010. p53-dependent regulation of autophagy protein LC3 supports cancer cell survival under prolonged starvation. Proc Natl Acad Sci 107: 18511-18516.

Schleicher ED, Weigert C. 2000. Role of the hexosamine biosynthetic pathway in diabetic nephropathy. Kidney Int Suppl 77: S13-S18.

Schmid T, Zhou J, Brüne B. 2004. HIF-1 and p53: Communication of transcription factors under hypoxia. $J$ Cell Mol Med 8: 423-431.

Schwartzenberg-bar-yoseph F, Armoni M, Karnieli E. 2004. The tumor suppressor p53 down-regulates glucose transporters GLUT1 and GLUT4 gene expression. Cancer Res 64: 2627-2633. 
Sen N, Satija YK, Das S. 2011. PGC-1 $\alpha$, a key modulator of p53, promotes cell survival upon metabolic stress. Mol Cell 44: 621-634.

Sena LA, Chandel NS. 2012. Physiological roles of mitochondrial reactive oxygen species. Mol Cell 48: 158-167.

Sermeus A, Michiels C. 2011. Reciprocal influence of the p53 and the hypoxic pathways. Cell Death Dis 2: e164.

Shizukuda Y, Matoba S, Mian OY, Nguyen T, Hwang PM. 2005. Targeted disruption of p53 attenuates doxorubicininduced cardiac toxicity in mice. Mol Cell Biochem 273: $25-32$.

Sinthupibulyakit C, Ittarat W, St. Clair WH, St. Clair DK. 2010. p53 protects lung cancer cells against metabolic stress. Int J Oncol 37: 1575-1581.

Son J, Lyssiotis C, Ying H, Wang X, Hua S, Ligorio M, Perera RM, Ferrone CR, Mullarky E, Shyh-Chang N, et al. 2013. Glutamine supports pancreatic cancer growth through a KRAS-regulated metabolic pathway. Nature 496: 101105.

Sowter HM, Ratcliffe PJ, Watson P, Greenberg AH, Harris AL. 2001. HIF-1-dependent regulation of hypoxic induction of the cell death factors BNIP3 and NIX in human tumors. Cancer Res 61: 6669-6673.

Stambolsky P, Weisz L, Shats I, Klein Y, Goldfinger N, Oren M, Rotter V. 2006. Regulation of AIF expression by p53. Cell Death Differ 13: 2140-2149.

Subbaramaiah K, Michaluart P, Chung WJ, Tanabe T, Telang N, Dannenberg AJ. 1999. Resveratrol inhibits cyclooxygenase-2 transcription in human mammary epithelial cells. Ann NY Acad Sci 889: 214-223.

Suzuki S, Tanaka T, Poyurovsky MV, Nagano H, Mayama T, Ohkubo S, Lokshin M, Hosokawa H, Nakayama T, Suzuki Y, et al. 2010. Phosphate-activated glutaminase (GLS2), a p53-inducible regulator of glutamine metabolism and reactive oxygen species. Proc Natl Acad Sci 107: 7461-7466.

Tan M, Li S, Swaroop M, Guan K, Oberley LW, Sun Y. 1999. Transcriptional activation of the human glutathione peroxidase promoter by p53. J Biol Chem 274: 12061-12066.

Tasdemir E, Maiuri MC, Galluzzi L, Vitale I, DjavaheriMergny M, D’Amelio M, Criollo A, Morselli E, Zhu C, Harper F, et al. 2008. Regulation of autophagy by cytoplasmic p53. Nat Cell Biol 10: 676-687.

Tu HC, Ren D, Wang GX, Chen DY, Westergard TD, Kim H, Sasagawa S, Hsieh JJD, Cheng EHY. 2009. The p53cathepsin axis cooperates with ROS to activate programmed necrotic death upon DNA damage. Proc Natl Acad Sci 106: 1093-1098.

Vahsen N, Candé C, Brière JJ, Bénit P, Joza N, Larochette N, Mastroberardino PG, Pequignot MO, Casares N, Lazar V, et al. 2004. AIF deficiency compromises oxidative phosphorylation. EMBO J 23: 4679-4689.

Vander Heiden MG, Cantley LC, Thompson CB. 2009. Understanding the Warburg effect: The metabolic requirements of cell proliferation. Science 324: 1029-1033.

Vazquez A, Oltvai ZN. 2011. Molecular crowding defines a common origin for the Warburg effect in proliferating cells and the lactate threshold in muscle physiology. PLoS ONE 6: 1-9.

Vazquez A, Markert EK, Oltvai ZN. 2011. Serine biosynthesis with one carbon catabolism and the glycine cleav- age system represents a novel pathway for ATP generation. PLoS ONE 6: 1-10.

Villeneuve NF, Sun Z, Chen W, Zhang DD. 2009. Nrf2 and p21 regulate the fine balance between life and death by controlling ROS levels. Cell Cycle 8: 3255-3256.

Voet D, Voet J. 2011. Biochemistry. Wiley, New York.

Vogelstein B, Lane D, Levine J. 2000. Surfing the p53 network. Nature 408: 307-310.

Vousden KH, Prives C. 2009. Blinded by the light: The growing complexity of p53. Cell 137: 413-431.

Vousden KH, Ryan KM. 2009. p53 and metabolism. Nat Rev Cancer 9: 691-700.

Wang J, Bin Erickson JW, Fuji R, Ramachandran S, Gao P, Dinavahi R, Wilson KF, Ambrosio ALB, Dias SMG, Dang CV, et al. 2010. Targeting mitochondrial glutaminase activity inhibits oncogenic transformation. Cancer Cell 18: 207-219.

Wang EY, Gang H, Aviv Y, Dhingra R, Margulets V, Kirshenbaum A, Kirshenbaum LA. 2013. p53 mediates autophagy and cell death by a mechanism contingent on Bnip3. Hypertension 62: 70-77.

Warburg O. 1956. On the origin of cancer cells. Science 123: 309-314.

Weidemann A, Johnson RS. 2008. Biology of HIF-1 $\alpha$. Cell Death Differ 15: 621-627.

Weinberg R. 2007. The biology of cancer. Garland Science, New York.

Wek RC, Jiang HY, Anthony TG. 2006. Coping with stress: eIF2 kinases and translational control. Biochem Soc Trans 34: 7-11.

Wellen KE, Thompson CB. 2010. Cellular metabolic stress: Considering how cells respond to nutrient excess. $\mathrm{Mol}$ Cell 40: $323-332$.

White E. 2012. Deconvoluting the context-dependent role for autophagy in cancer. Nat Rev Cancer 12: 401-410.

* White E. 2016. Autophagy and p53. Cold Spring Harb Perspect Med doi: 10.1101/cshperspect.a026120.

Yahagi N, Shimano H, Matsuzaka T, Najima Y, Sekiya M, Nakagawa Y, Ide T, Tomita S, Okazaki H, Tamura Y, et al. 2003. p53 activation in adipocytes of obese mice. J Biol Chem 278: 25395-25400.

Yellon DM, Hausenloy DJ. 2007. Myocardial reperfusion injury. N Engl J Med 357: 1121-1135.

Yoon K, Nakamura Y, Arakawa H. 2004. Identification of ALDH4 as a p53-inducible gene and its protective role in cellular stresses. J Hum Genet 49: 134-140.

Zaugg K, Yao Y, Reilly PT, Kannan K, Kiarash R, Mason J, Huang P, Sawyer SK, Fuerth B, Faubert B, et al. 2011. Carnitine palmitoyltransferase $1 \mathrm{C}$ promotes cell survival and tumor growth under conditions of metabolic stress. Genes Dev 25: 1041-1051.

Zhang J, Ney PA. 2009. Role of BNIP3 and NIX in cell death, autophagy, and mitophagy. Cell Death Differ 16: 939-946.

Zoncu R, Efeyan A, Sabatini DM. 2011a. mTOR: From growth signal integration to cancer, diabetes and ageing. Nat Rev Mol Cell Biol 12: 21-35.

Zoncu R, Bar-Peled L, Efeyan A, Wang S, Sancak Y, Sabatini DM. 2011b. mTORC1 senses lysosomal amino acids through an inside-out mechanism that requires the vacuolar $\mathrm{H}^{+}$-ATPase. Science 334: 678-683. 


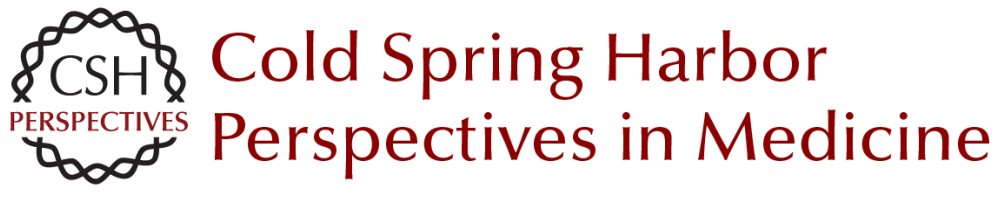

\section{Regulation of Cellular Metabolism and Hypoxia by p53}

Timothy J. Humpton and Karen H. Vousden

Cold Spring Harb Perspect Med 2016; doi: 10.1101/cshperspect.a026146

Subject Collection The p53 Protein

Targeting the MDM2-p53 Protein-Protein Interaction for New Cancer Therapy: Progress and Challenges

Shaomeng Wang, Yujun Zhao, Angelo Aguilar, et al.

Structural Evolution and Dynamics of the p53

Proteins

Giovanni Chillemi, Sebastian Kehrloesser,

Francesca Bernassola, et al.

Exploiting the p53 Pathway for Therapy Chit Fang Cheok and David Philip Lane

The Regulation of Cellular Functions by the p53

Protein: Cellular Senescence

Crystal A. Tonnessen-Murray, Guillermina Lozano and James G. Jackson

The Transactivation Domains of the p53 Protein Nitin Raj and Laura D. Attardi

The Evolution of the Ribosomal Protein-MDM2p53 Pathway

Chad Deisenroth, Derek A. Franklin and Yanping Zhang

Somatic TP53 Mutations in the Era of Genome

Sequencing

Pierre Hainaut and Gerd P. Pfeifer

The Paradox of p53: What, How, and Why?

Yael Aylon and Moshe Oren
Control of Cellular Aging, Tissue Function, and Cancer by p53 Downstream of Telomeres Caitlin M. Roake and Steven E. Artandi

Inherited TP53 Mutations and the $\mathbf{L i}-$ Fraumeni Syndrome

Tanya Guha and David Malkin

TP53 Mutations in Hypodiploid Acute Lymphoblastic Leukemia

Evan Q. Comeaux and Charles G. Mullighan

Transcriptional Regulation by Wild-Type and

Cancer-Related Mutant Forms of p53

Neil T. Pfister and Carol Prives

The Inherited p53 Mutation in the Brazilian

Population

Maria Isabel Achatz and Gerard P. Zambetti

TP53 Mutations in Breast and Ovarian Cancer Laxmi Silwal-Pandit, Anita Langerød and Anne-Lise Børresen-Dale

p53 and the Carcinogenicity of Chronic Inflammation

Andrei V. Gudkov and Elena A. Komarova

Oncogenic Mutant p53 Gain of Function

Nourishes the Vicious Cycle of Tumor

Development and Cancer Stem-Cell Formation

Yoav Shetzer, Alina Molchadsky and Varda Rotter

For additional articles in this collection, see http://perspectivesinmedicine.cshlp.org/cgi/collection/ 